\title{
The hyaluronic acid-HDAC3-miRNA network in allergic inflammation
}

\author{
Youngmi Kim, Sangkyung Eom, Deokbum Park, Hyuna Kim and Dooil Jeoung * \\ Department of Biochemistry, College of Natural Sciences, Kangwon National University, Chuncheon, South Korea
}

We previously reported the anti-allergic effect of high molecular weight form of hyaluronic acid (HMW-HA). In doing so, HA targets CD44 and inhibits FceRI signaling and cross-talk between epidermal growth factor receptor (EGFR) and FCeRI. We previously reported the role of histone deacetylases (HDACs) in allergic inflammation and allergic inflammationpromoted enhanced tumorigenic potential. We reported regulatory role of HA in the expression of HDAC3. In this review, we will discuss molecular mechanisms associated with anti-allergic effect of HA in relation with HDACs. The role of microRNAs (miRNAs) in allergic inflammation has been reported. We will also discuss the role of miRNAs in allergic inflammation in relation with HA-mediated anti-allergic effects.

\section{OPEN ACCESS}

Edited by:

David Naor,

Hebrew University of Jerusalem, Israel

Reviewed by:

Satoshi Tanaka,

Okayama University, Japan

Markku I. Tammi,

University of Eastern Finland, Finland

*Correspondence:

Dooil Jeoung,

Department of Biochemistry, College of Natural Sciences, Kangwon National University, Chuncheon

200-701, South Korea jeoungd@kangwon.ac.kr

Specialty section:

This article was submitted to Inflammation, a section of the journal

Frontiers in Immunology

Received: 05 January 2015 Accepted: 17 April 2015 Published: 30 April 2015

Citation:

Kim Y, Eom S, Park D, Kim H and Jeoung $D$ (2015) The hyaluronic acid-HDAC3-miRNA network in

allergic inflammation.

Front. Immunol. 6:210.

doi: 10.3389/fimmu.2015.00210
Keywords: allergic inflammation, CD44, histone deacetylase-3, hyaluronic acid, micro RNA genes

\section{The Role of Hyaluronic Acid in Allergic Inflammation}

Hyaluronic acid (HA), a major component of the extracellular matrix (ECM), plays a key role in regulating inflammation. HA enhances proteoglycan synthesis, reduces the production and activity of pro-inflammatory mediators and matrix metalloproteinases, and alters the behavior of immune cells (1). Inflammation is associated with accumulation and turnover of HA polymers by multiple cell types. Increased accumulation of HA has been demonstrated in joint tissue of rheumatoid arthritis (RA) patients (2); in lung disease, both in humans (3) and animal experimental models (4); in inflammatory liver disease; during vascular disease (5); in rejected kidney transplants (6) as well renal tissue of patients experiencing diabetic nephropathy (7); in the intestine of patients undergoing flares of inflammatory bowel disease (IBD) (8).

Circulating HA might be a marker of asthma control, as it correlates with airway resistance and has good sensitivity in the detection of impaired asthma control (9). The increased level of HA is correlated with asthma (10). In addition, HA appears to provide the scaffolding for inflammatory cell accumulation as well as for new collagen synthesis and deposition (10). HA deposition appears largely due to up-regulation of hyaluronan synthase 1 (HAS1) and hyaluronan synthase 2 (HAS2). HAS2 mRNA is markedly increased in asthmatic fibroblasts (11). In cases of inflammation, HA contains a variety of HA polymers with overlapping lengths and functions. HA exists as both a pro-and anti-inflammatory molecule in vivo, and these contradictory functions depend upon polymer length. High molecular weight form of hyaluronic acid (HMW-HA) elicits protective antiinflammatory effects that protect lung epithelial cells from apoptosis and is protective against liver injury, acting to reduce pro-inflammatory cytokines in a T-cell-mediated injury model (12). HMWHA inhibits macrophage proliferation and cytokine release, leading to decreased inflammation in the early wound of a preclinical post laminectomy rat model (13). HMW-HA exerts a negative effect on the activation of mitogen-activated protein kinase (MAPK) by allergic inflammation (14). HA with an average molecular mass $<500 \mathrm{kDa}$ can be considered a fragment. HA fragments with an average molecular weight of $200 \mathrm{kDa}$ have been shown to stimulate chemokines, cytokines, growth 
factors, proteases, and by macrophages (15-20). Organic contact sensitizers induce production of reactive oxygen species (ROS) and a concomitant breakdown of HA to pro-inflammatory low molecular weight fragments in the skin (21). Importantly, inhibition of either ROS-mediated or enzymatic HA breakdown prevents sensitization as well as elicitation of Chediak-Higashi Syndrome (CHS) (21). Mucus hyper secretion with elevated MUC5B mucin production is a pathologic feature in many airway diseases associated with oxidative stress (22). ROS-induced MUC5AC expression in normal human bronchial epithelial cells (NHBE) is dependent on HA depolymerization and epidermal growth factor receptor (EGFR)/MAPK activation (22). Although most of the work on low molecular weight HA (LMW-HA) fragments initially illustrated a pro-inflammatory response, a number of studies have shown that HA fragments can also be protective. In a murine model of colitis, intraperitoneal injection of $\mathrm{HA}<750 \mathrm{kDa}$ protects colonic epithelium in a Toll-like receptor (TLR) 4-dependent manner (23). This functional difference between HAs of varying sizes is a matter of controversy since many studies have reported opposing results in regard to which type of HA can bring about cellular changes (24). These contradictory functions of HA, depending on the polymer length, may result from differential effects of these HA on HA receptors such as CD44 and receptor for HA-mediated motility (RHAMM). Exogenous HAs used in many studies are not homogenous with respect to size. Therefore, it is difficult to conclude that size alone determines the function of HAs of various sizes. These discrepancies may also be due to differences in experimental settings, purity of HA (25), and the possibility of diverse responses to HA depending on the cell type. Although many reports suggest anti-allergic effect of exogenous HA, the effect of endogenous HMW-HA on the allergic inflammation needs further investigation.

Hyaluronic acid levels are elevated in allergic animals and the increase correlates with the influx of inflammatory cells. This increase in HA levels is largely due to up-regulation of hyaluronidase-1 (HYAL-1) and hyaluronidase-2 (HYAL-2) (26). HYAL-1, -2 , and -3 are expressed in airway epithelium and may operate in a coordinated fashion to depolymerize HA during allergen-induced asthmatic responses associated with up-regulation of tumor necrosis factor-alpha (TNF-alpha) and interleukin-1 beta (IL-1beta) (27). Degradation of HA by HYAL-1 primarily depends upon CD44 or other HA receptors to internalize HA fragments. Patients deficient in HYAL-1 have been reported with plasma HA levels at 40 times normal (28). The finding of HYAL-2 in complex with CD44 at the plasma membrane suggests that HA-binding proteins may enhance the activity of HA degrading enzymes, and CD44 binding may provide HYAL-2 with a preferable conformation of HA. IL-1beta exerts inflammatory activity via CD44 by the mediation of HA fragments derived from HA depolymerization (29).

CD44, a receptor for HA, expressed on CD4 $(+) \mathrm{T}$ cells plays a critical role in the accumulation of antigen-specific Th2 cells, but not Th1 cells, in the airway and in the development of airway hyper-responsiveness (AHR) induced by antigen challenge (30). Airway fibroblasts from patients with asthma produced significantly increased concentrations of LMW-HA compared with those of normal fibroblasts (30). CD44, but not CD62L, is required for leukocyte extravasations during a Th2-type inflammatory response such as allergic dermatitis (31). HMW-HA inhibits interaction between $\operatorname{IgE}$ and $\mathrm{Fc} \varepsilon \mathrm{RI}$ and between $\mathrm{Fc} \varepsilon \mathrm{RI}$ and protein kinase $\mathrm{C} \delta(\mathrm{PKC} \delta)$ during allergic inflammation (14). A role for CD44 in the regulation of allergic inflammation in vivo has been shown by studies in which anti-CD44 treatment inhibited the development of optimal contact allergic responses (32). CD44 has been shown to be responsible for the development of pulmonary eosinophilia (33). CD44-hyaluronan interaction is necessary for allergic asthma (34). The serum-derived hyaluronanassociated protein (SHAP)-HA complex has an inhibitory role in the development of airway hyper responsiveness and allergic airway inflammation which may be attributed, at least in part, to negative feedback mechanisms exerted by SHAP (35). It will be necessary to examine effects of HAs of various sizes on the expression and/or activity of CD44.

\section{The Role of HDAC3 in Allergic Inflammation}

Histone acetylation/deacetylation plays an important role in the regulation of inflammatory genes associated with allergic inflammation (36). Histone deacetylase-3 (HDAC3)-deficient macrophages are unable to activate almost half of the inflammatory gene expression program when stimulated with lipopolysaccharide (LPS) (37). Pulmonary inflammation is ameliorated in mice lacking HDAC3 in macrophages (38). The induction of cyclooxygenase (COX)-2, which occurs during allergic inflammation, is accompanied by degradation of HDAC1 (39). HDAC2 expression and activity are decreased in asthmatic subjects, smokers, and smoking asthmatic subjects (40). HDAC3, induced by antigen stimulation, interacts with $\mathrm{F} c \varepsilon \mathrm{RI}$ and is necessary for allergic inflammation both in vitro and in vivo (41). DNA methyl transferase I (DNMT1) acts as a negative regulator of allergic inflammation and the down-regulation of DNMT1 induces the expression of HDAC3 (42). HDAC3 is necessary for the induction of TNF- $\alpha$, a cytokine increased during allergic inflammation, in cardiomyocytes during LPS stimulation (43). HDAC3 mediates allergic inflammation by regulating the expression of monocyte chemoattractant protein-1 (MCP1) (41). HMW-HA, but not LMW-HASs, decreases the expression of HDAC3 in human vascular endothelial cells to promote angiogenesis which is accompanied by allergic inflammation (44).

\section{Role of miRNAs in Allergic Inflammation}

microRNAs (miRNAs) are small (20-23 nucleotides), singlestranded non-coding RNAs that play important roles in the posttranscriptional regulation of gene expression in mammalian cells by regulating translation. Upon binding of their $5^{\prime}$ extremity (seed sequence encompassing nucleotides $2-7$ or $2-8$ ) with a complementary site located most of the time in the $3^{\prime}$ un-translated region ( $3^{\prime} \mathrm{UTR}$ ) of target mRNAs, miRNAs alter gene expression by translational repression or RNA degradation (45). Because miRNAs regulate the expression of transcription factors that regulate the expression of miRNAs themselves, miRNAs form feedback loops. miR-384 and HDAC3 form a negative feedback loop to regulate allergic inflammation [(46), Figure 1A]. This suggests the involvement of miR-384 in the anti-allergic effect of HA. Several 


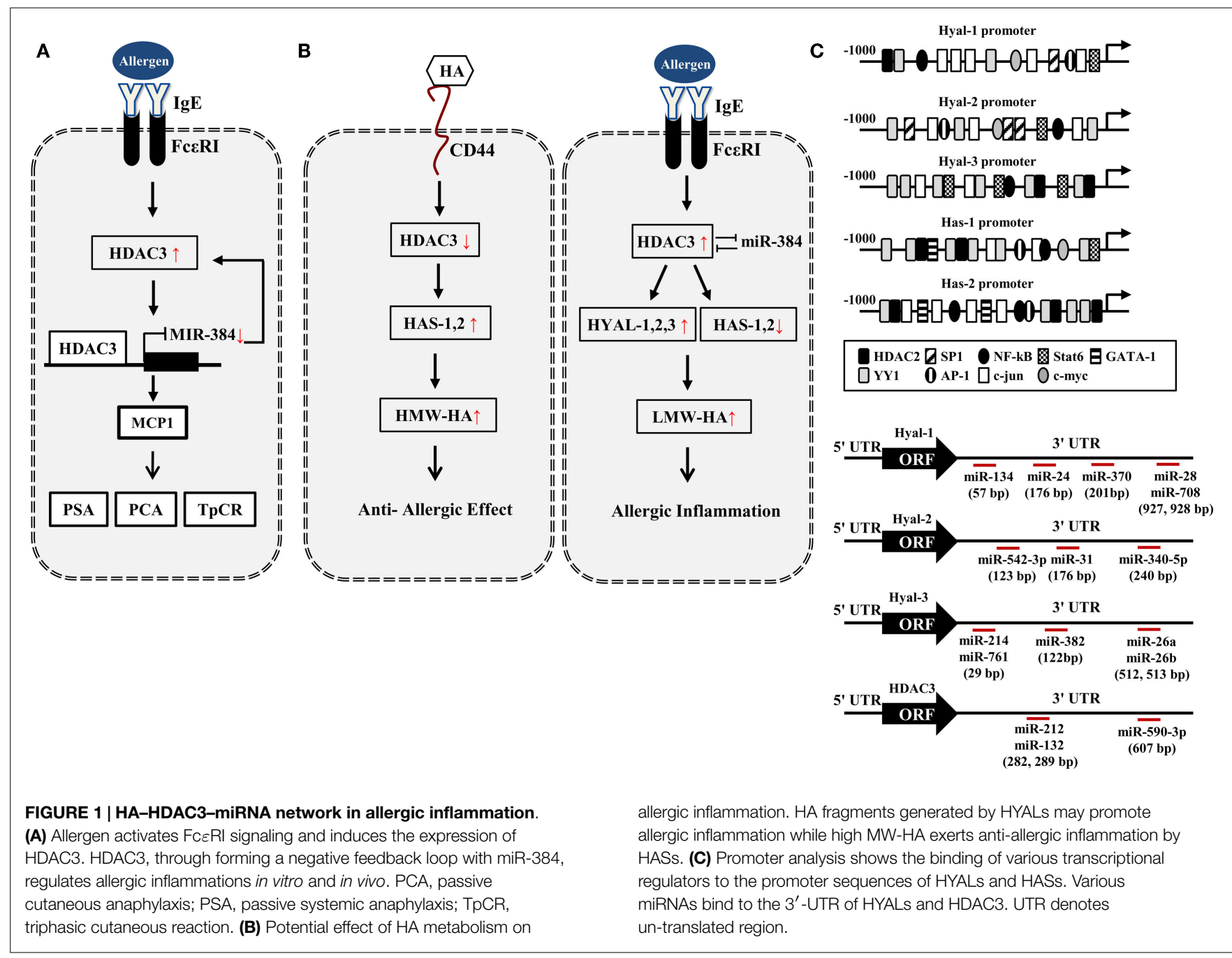

reports suggest role of HDACs in the expression regulation of miRNAs (47-50). miRNA let-7a regulates the expression of IL13, a cytokine necessary for allergic lung disease (51). The downregulation of miR-145 inhibits Th 2 cytokine production and AHR (52). HA-CD44 interaction enhances the expression of miR-10b (53). miR-199a-3p and miR-34a miR-590-3p target CD44 $(54,55)$. Polymorphisms of CD44 $3^{\prime}$ UTR weaken the binding of miRNAs (55), suggesting that miRNAs regulate the expression of CD44. Given the fact that CD44 is involved in allergic inflammation, miRNAs may regulate HA-mediated anti-allergic inflammation.

\section{The Regulation of HA Metabolism by miRNAs and HDAC3}

In silico screening of expression data with predicted miR-23 target sites combined with in vivo testing, predicts HAS2 as novel direct target of miR-23 (56). miR-23a-3p in non-senescent fibroblasts leads to the decreased HAS2-mediated HA synthesis (57). This implies that miR-23 may regulate the production of HA during allergic inflammation. Based on our previous report (44), HA-CD44 may decrease the expression of HDAC3 (Figure 1B). Promoter analysis shows that HAS1 and HAS2 contain the binding sites for YY1, STAT6, NF-kB, and HDAC2 (Figure 1C), suggesting that the production of HA is under epigenetic regulation. Because HDAC3 shows an inverse relationship with HDAC2 (41), HDAC3 may regulate the expression of HASs to mediate allergic inflammation. Many reports suggest that HASs may increase the production of HMW-HA to exert anti-allergic effects (Figure 1B). Thus, the decreased expression of HDAC3 by HA-CD44 interaction may increase the expression of HAS1 and HAS2 to exert anti-allergic effect (Figure 1B). HDAC3, increased during allergic inflammation, may regulate the expression of HYALs and HASs differentially to increase the production of LMW-HA. This may result in allergic inflammation (Figure 1B).

Promoter analysis shows that HYAL-1, -2 , and -3 contain binding sites for various transcriptional regulators including HDAC2 (Figure 1C), suggesting the role of HDAC3 in the expression regulation of HYALs. TargetScan analysis predicts the binding of miRNAs, such as miR-24,-28, -134, and -370, to the $3^{\prime}$-UTR sequences of HYAL-1 (Figure 1C). TargetScan analysis predicts the binding of various miRNAs to the $3^{\prime}$-UTR sequences of HYAL-2 and HYAL-3 (Figure 1C). These miRNAs may prevent the production of HA fragments by negatively regulating the expression of these HYALs. Thus, these miRNAs may mediate 
allergic inflammation. TargetScan analysis predicts the binding of miR-212,-132, and -590 to the $3^{\prime}$-UTR of HDAC3 (Figure 1C). These miRNAs may exert anti-allergic effects by decreasing the expression of HDAC3. Taken together, miRNAs and HDAC3 may regulate allergic inflammation through their effects on HA metabolism.

\section{Concluding Remarks and Perspectives}

In this study, we show the possible involvement of miRNAs and HDAC3 in the regulation of HA metabolism. HA-HDAC3 -miRNA network described in this review may offer valuable mechanism for HA-mediated anti-allergic effects. For better understanding of HA-mediated anti-allergic effect, it will be

\section{References}

1. Moreland LW. Intra-articular hyaluronan (hyaluronic acid) and hylans for the treatment of osteoarthritis: mechanisms of action. Arthritis Res Ther (2003) 5:54-67. doi:10.1186/ar855

2. Dahl LB, Dahl IM, Engstrom-Laurent A, Granath K. Concentration and molecular weight of sodium hyaluronate in synovial fluid from patients with rheumatoid arthritis and other arthropathies. Ann Rheum Dis (1985) 44:817-22. doi:10. 1136/ard.44.12.817

3. Hallgren R, Samuelsson T, Laurent TC, Modig J. Accumulation of hyaluronan (hyaluronic acid) in the lung in adult respiratory distress syndrome. Am Rev Respir Dis (1989) 139:682-7. doi:10.1164/ajrccm/139.3.682

4. Jiang D, Liang J, Fan J, Yu S, Chen S, Luo Y, et al. Regulation of lung injury and repair by toll-like receptors and hyaluronan. Nat Med (2005) 11:1173-9. doi: $10.1038 / \mathrm{nm} 1315$

5. Waldenstrom A, Martinussen HJ, Gerdin B, Hallgren R. Accumulation of hyaluronan and tissue edema in experimental myocardial infarction. J Clin Invest (1991) 88:1622-8. doi:10.1172/JCI115475

6. Wells AF, Larsson E, Tengblad A, Fellstrom B, Tufveson G, Klareskog L, et al. The localization of hyaluronan in normal and rejected human kidneys. Transplantation (1990) 50:240-3. doi:10.1097/00007890-199008000-00014

7. Lewis A, Steadman R, Manley P, Craig K, dela Motte C, Hascall V, et al. Diabetic nephropathy, inflammation, hyaluronan and interstitial fibrosis. Histol Histopathol (2008) 23:731-9.

8. dela Motte CA, Hascall VC, Drazba J, Bandyopadhyay SK, Strong SA. Mononuclear leukocytes bind to specific hyaluronan structures on colon mucosal smooth muscle cells treated with polyinosinic acid: polycytidylic acid: inter alpha-trypsin inhibitor is crucial to structure and function. Am J Pathol (2003) 163:121-33. doi:10.1016/S0002-9440(10)63636-X

9. Eszes N, Toldi G, Bohács A, Ivancsó I, Müller V, Rigó J Jr, et al. Relationship of circulating hyaluronic acid levels to disease control in asthma and asthmatic pregnancy. PLoS One (2014) 9:e94678. doi:10.1371/journal.pone. 0094678

10. Cheng G, Swaidani S, Sharma M, Lauer ME, Hascall VC, Aronica MA. Correlation of hyaluronan deposition with infiltration of eosinophils and lymphocytes in a cockroach-induced murine model of asthma. Glycobiology (2013) 23:43-58. doi:10.1093/glycob/cws122

11. Liang J, Jiang D, Jung Y, Xie T, Ingram J, Church T, et al. Role of hyaluronan and hyaluronan-binding proteins in human asthma. J Allergy Clin Immunol (2011) 128:403-11. doi:10.1016/j.jaci.2011.04.006

12. Nakamura K, Yokohama S, Yoneda M, Okamoto S, Tamaki Y, Ito T, et al. High, but not low, molecular weight hyaluronan prevents T-cell-mediated liver injury by reducing proinflammatory cytokines in mice. J Gastroenterol (2004) 39:346-54. doi:10.1007/s00535-003-1301-x

13. Schimizzi AL, Massie JB, Murphy M, Perry A, Kim CW, Garfin SR, et al. High molecular-weight hyaluronan inhibits macrophage proliferation and cytokine release in the early wound of a preclinical post laminectomy rat model. Spine $J$ (2006) 6:550-6. doi:10.1016/j.spinee.2005.12.005

14. Kim Y, Lee YS, Hahn JH, Choe J, Kwon HJ, Ro JY, et al. Hyaluronic acid targets CD44 and inhibits FcepsilonRI signaling involving PKCdelta, Rac1, necessary to identify downstream targets of HA. The downstream targets of HA would be valuable for the development of anti-allergic drugs. Identification of more miRNAs that regulate allergic inflammation in relation to HA and HDAC3 will be necessary for better understanding of HA-mediated anti-allergic inflammation.

\section{Acknowledgments}

This work was supported by National Research Foundation Grant 2014R1A2A2A01002448, a grant from the BK21 Plus program, a grant from National R\&D Program for Cancer Control, Ministry for Health and Welfare, Republic of Korea, Grant 1320160, and a grant from Kangwon National University (C1011923-01-01).

ROS, and MAPK to exert anti-allergic effect. Mol Immunol (2008) 45:2537-47. doi:10.1016/j.molimm.2008.01.008

15. Horton MR, Burdick MD, Strieter RM, Bao C, Noble PW. Regulation of hyaluronan-induced chemokine gene expression by IL-10 and IFN-gamma in mouse macrophages. J Immunol (1998) 160:3023-30.

16. Horton MR, McKee CM, Bao C, Liao F, Farber JM, Hodge-Du Four J, et al. Hyaluronan fragments synergize with interferon-gamma to induce the C-X-C chemokines mig and interferon-inducible protein-10 in mouse macrophages. J Biol Chem (1998) 273:35088-94. doi:10.1074/jbc.273.52.35088

17. Horton MR, Olman MA, Noble PW. Hyaluronan fragments induce plasminogen activator inhibitor-1and inhibit urokinase activity in mouse alveolar macrophages: a potential mechanism for impaired fibrinolytic activity in acute lung injury. Chest (1999) 116:17S.

18. Horton MR, Shapiro S, Bao C, Lowenstein CJ, Noble PW. Induction and regulation of macrophage metalloelastase by hyaluronan fragments in mouse macrophages. J Immunol (1999) 162:4171-6.

19. Noble PW, Lake FR, Henson PM, Riches DW. Hyaluronate activation of CD44 induces insulin-like growthfactor-1 expression by a tumor necrosis factor-alphadependent mechanism in murine macrophages. JClin Invest (1993) 91:2368-77. doi:10.1172/JCI116469

20. McKee CM, Penno MB, Cowman M, Burdick MD, Strieter RM, Bao C, et al. Hyaluronan (HA) fragments induce chemokine gene expression in alveolar macrophages. The role of HA size and CD44. J Clin Invest (1996) 98:2403-13. doi:10.1172/JCI119054

21. Esser PR, Wölfle U, Durr C, von Loewenich FD, Schempp CM, Freudenberg $\mathrm{MA}$, et al. Contact sensitizers induce skin inflammation via ROS production and hyaluronic acid degradation. PLoS One (2012) 7:e41340. doi:10.1371/ journal.pone.0041340

22. Casalino-Matsuda SM, Monzon ME, Day AJ, Forteza RM. Hyaluronan fragments/CD44 mediate oxidative stress-induced MUC5B up-regulation in airway epithelium. Am J Respir Cell Mol Biol (2009) 40:277-85. doi:10.1165/rcmb. 2008-0073OC

23. Zheng L, Riehl TE, Stenson WF. Regulation of colonic epithelial repair in mice by toll-like receptors and hyaluronic acid. Gastroenterology (2009) 137:2041-51. doi:10.1053/j.gastro.2009.08.055

24. McKee CM, Lowenstein CJ, Horton MR, Wu J, Bao C, Chin BY, et al. Hyaluronan fragments induce nitric-oxide synthase in murine macrophages through a nuclear factor kappaB-dependent mechanism. J Biol Chem (1997) 272:8013-8. doi:10.1074/jbc.272.12.8013

25. McDonald JA, Camenisch TD. Hyaluronan: genetic insights into the complex biology of a simple polysaccharide. Glycoconj J (2003) 19:331-9. doi:10.1023/A: 1025369004783

26. Ghosh S, Samarasinghe AE, Hoselton SA, Dorsam GP, Schuh JM. Hyaluronan deposition and co-localization with inflammatory cells and collagen in a murine model of fungal allergic asthma. Inflamm Res (2014) 63:475-84. doi:10.1007/ s00011-014-0719-3

27. Monzón ME, Manzanares D, Schmid N, Casalino-Matsuda SM, Forteza RM. Hyaluronidase expression and activity is regulated by pro-inflammatory cytokines in human airway epithelial cells. Am J Respir Cell Mol Biol (2008) 39:289-95. doi:10.1165/rcmb.2007-0361OC 
28. Triggs-Raine B, Salo TJ, Zhang H, Wicklow BA, Natowicz MR. Mutations in HYAL1, a member of a tandemly distributed multigene family encoding disparate hyaluronidase activities, cause a newly described lysosomal disorder, mucopolysaccharidosis IX. Proc Nat l Acad Sci U S A (1999) 96:6296-300. doi:10.1073/pnas.96.11.6296

29. Campo GM, Avenoso A, D’Ascola A, Scuruchi M, Prestipino V, Calatroni A, et al. Hyaluronan in part mediates IL-1beta-induced inflammation in mouse chondrocytes by up-regulating CD44 receptors. Gene (2012) 494:24-35. doi:10. 1016/j.gene.2011.11.064

30. Katoh S, Kaminuma O, Hiroi T, Mori A, Ohtomo T, Maeda S, et al. CD44 is critical for airway accumulation of antigen-specific Th2, but not Th1, cells induced by antigen challenge in mice. Eur J Immunol (2011) 41:3198-207. doi:10.1002/eji.201141521

31. Gonda A, Gál I, Szántó S, Sarraj B, Glant TT, Hunyadi J, et al. CD44, but not l-selectin, is critically involved in leucocyte migration into the skin in a murine model of allergic dermatitis. Exp Dermatol (2005) 14:700-8. doi:10. 1111/j.0906-6705.2005.00348.x

32. Camp RL, Scheynius A, Johansson C, Pure E. CD44 is necessary for optimal contact allergic responses but is not required for normal leukocyte extravasation. J Exp Med (1993) 178:497-507. doi:10.1084/jem.178.2.497

33. Katoh S, Matsumoto N, Kawakita K, Tominaga A, Kincade PW, Matsukura S. A role for CD44 in an antigen-induced murine model of pulmonary eosinophilia. J Clin Invest (2003) 111:1563-70. doi:10.1172/JCI16583

34. Katoh S, Ishii N, Nobumoto A, Takeshita K, Dai SY, Shinonaga R, et al. Galectin9 inhibits CD44-hyaluronan interaction and suppresses a murine model of allergic asthma. Am J Respir Crit Care Med (2007) 176:27-35. doi:10.1164/rccm. 200608-1243OC

35. Zhu L, Zhuo L, Kimata K, Yamaguchi E, Watanabe H, Aronica MA, et al. Deficiency in the serum-derived hyaluronan-associated protein-hyaluronan complex enhances airway hyperresponsiveness in a murine model of asthma. Int Arch Allergy Immunol (2010) 153:223-33. doi:10.1159/000314362

36. Bhavsar P, Ahmad T, Adcock IM. The role of histone deacetylases in asthma and allergic diseases. J Allergy Clin Immunol (2008) 121:580-4. doi:10.1016/j. jaci.2007.12.1156

37. Chen X, Barozzi I, Termanini A, Prosperini E, Recchiuti A, Dalli J, et al. Requirement for the histone deacetylase Hdac3 for the inflammatory gene expression program in macrophages. Proc Natl Acad Sci U S A (2012) 109:2865-74. doi:10. 1073/pnas.1121131109

38. Mullican SE, Gaddis CA, Alenghat T, Nair MG, Giacomin PR, Everett LJ, et al. Histone deacetylase 3 is an epigenomic brake in macrophage alternative activation. Genes Dev (2011) 25:2480-8. doi:10.1101/gad.175950.111

39. Cao D, Bromberg PA, Samet JM. COX-2 expression induced by diesel particles involves chromatin modification and degradation of HDAC1. Am J Respir Cell Mol Biol (2007) 37:232-9. doi:10.1165/rcmb.2006-0449OC

40. Adcock IM, Ford P, Ito K, Barnes PJ. Epigenetics and airways disease. Respir Res (2006) 7:21. doi:10.1186/1465-9921-7-21

41. Kim Y, Kim K, Park D, Lee E, Lee H, Lee YS, et al. Histone deacetylase 3 mediates allergic skin inflammation by regulating expression of MCP1 protein. J Biol Chem (2012) 287:25844-59. doi:10.1074/jbc.M112.348284

42. Kim Y, Kim K, Park D, Lee E, Lee H, Lee YS, et al. DNA methyl transferase I acts as a negative regulator of allergic skin inflammation. Mol Immunol (2013) 53:1-14. doi:10.1016/j.molimm.2012.06.010

43. Zhu H, Shan L, Schiller PW, Mai A, Peng T. Histone deacetylase-3 activation promotes tumor necrosis factor- $\alpha$ (TNF- $\alpha$ ) expression in cardiomyocytes during lipopolysaccharide stimulation. J Biol Chem (2010) 285:9429-36. doi:10. 1074/jbc.M109.071274

44. Park D, Kim Y, Kim H, Kim K, Lee YS, Choe J, et al. Hyaluronic acid promotes angiogenesis by inducing RHAMM-TGF $\beta$ receptor interaction via CD44-PKCס. Mol Cells (2012) 33:563-74. doi:10.1007/s10059-012-2294- 1
45. Pasquinelli AE. MicroRNAs and their targets: recognition, regulation and an emerging reciprocal relationship. Nat Rev Genet (2012) 13:271-82. doi:10.1038/ nrg3162

46. Eom S, Kim Y, Park D, Lee H, Lee YS, Choe J, et al. Histone deacetylase-3 mediates positive feedback relationship between anaphylaxis and tumor metastasis. J Biol Chem (2014) 289:12126-44. doi:10.1074/jbc.M113.521245

47. Zhou R, Gong AY, Chen D, Miller RE, Eischeid AN, Chen XM. Histone deacetylases and NF-kB signaling coordinate expression of CX3CL1 in epithelial cells in response to microbial challenge by suppressing miR-424 and miR-503. PLoS One (2013) 8:e65153. doi:10.1371/journal.pone.0065153

48. Kaluza D, Kroll J, Gesierich S, Manavski Y, Boeckel JN, Doebele C, et al. Histone deacetylase 9 promotes angiogenesis by targeting the antiangiogenic microRNA-17-92 cluster in endothelial cells. Arterioscler Thromb Vasc Biol (2013) 33:533-43. doi:10.1161/ATVBAHA.112.300415

49. Chatterjee N, Wang WL, Conklin T, Chittur S, Tenniswood M. Histone deacetylase inhibitors modulate miRNA and mRNA expression, block metaphase, and induce apoptosis in inflammatory breast cancer cells. Cancer Biol Ther (2013) 14:658-71. doi:10.4161/cbt.25088

50. Chen CQ, Chen CS, Chen JJ, Zhou LP, Xu HL, Jin WW, et al. Histone deacetylases inhibitor trichostatin A increases the expression of Dleu2/miR-15a/16-1 via HDAC3 in non-small cell lung cancer. Mol Cell Biochem (2013) 383:137-48. doi:10.1007/s11010-013-1762-z

51. Polikepahad S, Knight JM, Naghavi AO, Oplt T, Creighton CJ, Shaw C, et al. Proinflammatory role for let-7 microRNAs in experimental asthma. J Biol Chem (2010) 285:30139-49. doi:10.1074/jbc.M110.145698

52. Collison A, Mattes J, Plank M, Foster PS. Inhibition of house dust mite-induced allergic airways disease by antagonism of microRNA-145 is comparable to glucocorticoid treatment. J Allergy Clin Immunol (2011) 128:160-7. doi:10. 1016/j.jaci.2011.04.005

53. Bourguignon LY, Wong G, Earle C, Krueger K, Spevak CC. HyaluronanCD44 interaction promotes c-Src-mediated twist signaling, microRNA-10b expression, and RhoA/RhoC up-regulation, leading to Rho-kinase-associated cytoskeleton activation and breast tumor cell invasion. J Biol Chem (2010) 285:36721-35. doi:10.1074/jbc.M110.162305

54. Henry JC, Park JK, Jiang J, Kim JH, Nagorney DM, Roberts LR, et al. miR199a-3p targets CD44 and reduces proliferation of CD44 positive hepatocellular carcinoma cell lines. Biochem Biophys Res Commun (2010) 403:120-5. doi:10. 1016/j.bbrc.2010.10.130

55. Lou F, Ma HN, Xu L, Chen M, Zhu YB. Two polymorphisms of CD44 3'UTR weaken the binding of miRNAs and associate with naso-pharyngeal carcinoma in a Chinese population. Eur Rev Med Pharmacol Sci (2014) 18:2444-52.

56. Lagendijk AK, Goumans MJ, Burkhard SB, Bakkers J. MicroRNA-23 restricts cardiac valve formation by inhibiting Has2 and extracellular hyaluronic acid production. Circ Res (2011) 109:649-57. doi:10.1161/CIRCRESAHA.111. 247635

57. Röck K, Tigges J, Sass S, Schütze A, Florea AM, Fender AC, et al. miR-23a3 p causes cellular senescence by targeting hyaluronan synthase 2: possible implication for skin aging. J Invest Dermatol (2015) 135:369-77. doi:10.1038/ jid.2014.422

Conflict of Interest Statement: The authors declare that the research was conducted in the absence of any commercial or financial relationships that could be construed as a potential conflict of interest.

Copyright (c) $2015 \mathrm{Kim}$, Eom, Park, Kim and Jeoung. This is an open-access article distributed under the terms of the Creative Commons Attribution License (CC BY). The use, distribution or reproduction in other forums is permitted, provided the original author(s) or licensor are credited and that the original publication in this journal is cited, in accordance with accepted academic practice. No use, distribution or reproduction is permitted which does not comply with these terms. 